\title{
Analysis of psychometric features of the Mini-Mental State Examination and the Montreal Cognitive Assessment methods
}

\author{
0. Kabátová, S. Puteková, J. Martinková, M. Súkenníková
}

Original Articles

Trnava University, Faculty of Health and Social Work, Department of Nursing, Trnava, Slovak Republic

\section{Correspondence to:}

Trnava University in Trnava, Faculty of Health Sciences and Social Work,

Univerzitné nám. 191843 Trnava, Slovak Republic; E-mail: olga.kabatova@truni.sk

Submitted: 23.2.2016

Revised: 13.7.2016

Accepted: 5.8.2016

\section{Reviewers:}

J. Nzau Mavole

The Catholic University of Eastern Africa, Nairobi, Kenya

M. Bartkovjak

Hospital in Marial Lou, AAA organization, South Sudan

\section{Key words:}

Cognitive disorders. Screening. MMSE. MoCA. Analysis.

CSWHI 2016; 7(2): 62-69 @ 2016 Clinical Social Work and Health Intervention

\section{Abstract:}

This study aim was to analyse selected psychometric features of the Mini-Mental State Exam (MMSE) and the Montreal Cognitive Assessment (MoCA) methods. The Montreal Cognitive Assessment (MoCA) was developed to enable earlier detection of mild cognitive impairment (MCI) relative to familiar multi-domain tests like the Mini-Mental State Exam (MMSE). Clinicians need to better understand the relationship between MoCA and MMSE scores. The analysis was performed on a sample of 84 geriatric patients. We have found a concurrent validity by calculation of Pearson's correlation coefficient between the test scores of the MMSE and the MoCA methods $(\mathrm{r}(84)=0.77, \mathrm{P}<0.001)$. Based on the correlation analysis, it may be stated that the MMSE test score is in a very tight positive correlation with the test score of the MoCA. We have also performed reliability analysis of both screening methods by calculation of internal consistency. The internal consistency of the MMSE method was represented by Cronbach's alpha at the level of 0.78 , and the MoCA method at the level of 0.81 ; those are considered to be optimum 
values. The MMSE sensitivity was good, and that was at the level = 0.83 with a confidence interval $95 \%$ from 0.62 to 0.95 . The MoCA sensitivity was very good, and that was at the level $=0.98$ with $95 \%$ of the confidence interval from 0.80 to 0.99 . The MMSE specificity was very good, and that was at the level $=0.99$ with $95 \%$ of the confidence interval from 0.92 to 0.99 . The MoCA specificity was good, and that was at the level $=0.85$ with $95 \%$ of the confidence interval from 0.73 to 0.91 . We have demonstrated a good internal consistency for both of the methods, and that means these screening methods are stable at the time and they provide reliable measuring of cognitive deficit.

\section{Introduction}

Cognitive disorders and dementia represent a serious health issue of older population. Due to high financial costs and social consequences they are becoming an issue of the whole society as well. Their prevalence is high in old age: $5-10 \%$ of dementias, $17 \%$ of mild cognitive impairment, and app. 20\% of benign age-influenced changes (Mauk, 2013). With the mean life expectancy rising, incidence of cognitive disorders will also be rising (Smith, Bondi, 2013). Despite this fact, $49 \%$ of the general practitioners do not examine cognitive functions in elderly patients at all or only occasionally, other $18 \%$ of them would perform this examination but they do not know how, and $12 \%$ of them do not have time for this diagnostics. Standardised tests are known only to $8 \%$ of the general practitioners and only half of them use it. Therefore, the alarming $60-70 \%$ of geriatric patients with dementia in higher age are not usually diagnosed (Topinková, Jirák, Kožený, 2002). Cognitive examination performed by screening tests is a necessary part of cognitive disorders diagnostics. In appropriate usage, the screening tests of cognitive functions may reveal partial stage of cognitive deficit. The results of screening methods should be in compliance with the information about the patient's problems which are communicated by conversation with the patient and persons in their proximate surrounding. However, complex neuropsychological examination is essential for thorough specification of cognitive deficiency. The same applies not only to mild cognitive impairment study but mainly for pre-clinic study of neurodegenerative diseases leading to cognitive deficit, when the first cognitive problems might occur, which are sensed subjectively by the patient $(\mathrm{Tu}-$ okko, Hultsch, 2013). Cognitive disorders assessment in context of recognition need is a part of complex assessment of a geriatric patient and it is based on the data gained by various methods. It does not replace clinic examination and it is understood as a supplementary method to other methods of data collection (Barker, Board, 2012). The most widespread short screening test is the Test MMSE - Mini-Mental State Examination, which evaluates orientation, extent of attention, attention and calculation, memory and language (Folstein, Folstein, McHugh, 1975). Due to low sensitivity, however, it is rather inappropriate in mild cognitive impairment diagnostics and it is particularly applied in dementia syndrome diagnostics. Low sensitivity in patients with mild cognitive impairment is caused by relative simplicity of the test in relation to memory and low representation of items which test the memory, and also by absence of tasks for frontal functions such as planning, 
decision-making, attention and others. The second mostly used short screening test for cognitive functions evaluation is the MoCA - Montreal Cognitive Assessment (Nasreddine et al., 2005). Out of the cognitive skills, the MoCA is focused on visuospatial functions, naming, and memory including delayed recall, attention, language, abstraction and orientation. It means that it encompasses greater spectrum of tasks demanding of executive functions and in all it is more difficult test than the MMSE. Advantage of the MoCA is sensitivity rise of the test in patients with mild cognitive impairment without significant impact on specificity, and at the same time still relatively short period of administration.

\section{Patients and Methods}

Analysis of psychometric features of the MMSE and MoCA methods was performed on a sample of 84 geriatric patients. With regard to gender, the examined group was formed by 29 men $(35 \%$ of $\mathrm{N}=84)$ and 55 women $(65 \%$ of $\mathrm{N}=84)$. The mean age of the examined group was $77(\mathrm{SD}=3.9)$ with the variation span of 12 years; the minimum age of $71(\mathrm{~N}=10)$ and maximum age of 83 years $(\mathrm{N}=4)$. In the group of men the mean age was $76.5(\mathrm{SD}=4.4)$ and in the group of women 77.2 ( $\mathrm{SD}=3.6)$. The selection criteria for geriatric patient classification into the examined group were: the age of 65 and more, willingness and ability to cooperate, the language kept, fine motor movement, sight and hearing. The data collection was taking place from July 2015 to February 2016. We found the concurrent validity by calculation of Pearson's correlation coefficient between the test scores of the MMSE and MoCA methods. We have also performed reliability analysis of both screening methods by calculation of internal consistency of both screening methods. We determined the sensitivity and specificity based on dementia diagnosis in comparison with the critical cut off score of 26 points, and that was both for the MMSE methodology as well as the MoCA, so called gained test score of 25 and less represented cognitive deficit.

\section{Results and Discussion}

First, we analysed the concurrent, or also so called diagnostic, validity which is represented by Pearson's correlation coefficient between the test scores of the MMSE and MoCA methods; $r(84)=0.77, \mathrm{P}<$ 0.001 . Based on the correlative analysis, we can state that the test score of the MMSE is in a very tight positive correlation with the test score of the MoCA which is graphically illustrated by the means of correlation diagram (Graph 1). In the graph, there are geriatric patients marked by red who had dementia diagnosis confirmed and there are geriatric patients without dementia diagnosis marked by blue.

Also, we have performed reliability analysis of both screening methods. Internal consistency of the MMSE method was represented by Cronbach's alpha at the level of 0.78 and the MoCA method at the level of 0.81 . The optimum value of Cronbach's alpha, which points to sufficient internal consistency of the method, is considered the value from 0.7 up to 0.9 (see e.g. Tavakol, Dennick, 2011). We determined the sensitivity and specificity based on dementia diagnosis in comparison with the critical cut off score $=26$ points for both the MMSE method as well as the MoCA method, the so called gained test score of 25 points and less represents cognitive deficit or dementia. The MMSE sensitivity was good, and that was at the level $=0.83$ with $95 \%$ of the confidence interval from 0.62 to 0.95 . The MoCA sensitivity was very good, and that was at the level $=0.98$ with $95 \%$ of the confidence interval from 0.80 to 0.99 . The 
Graph 1 Correlation diagram score of the MMSE with the MoCA

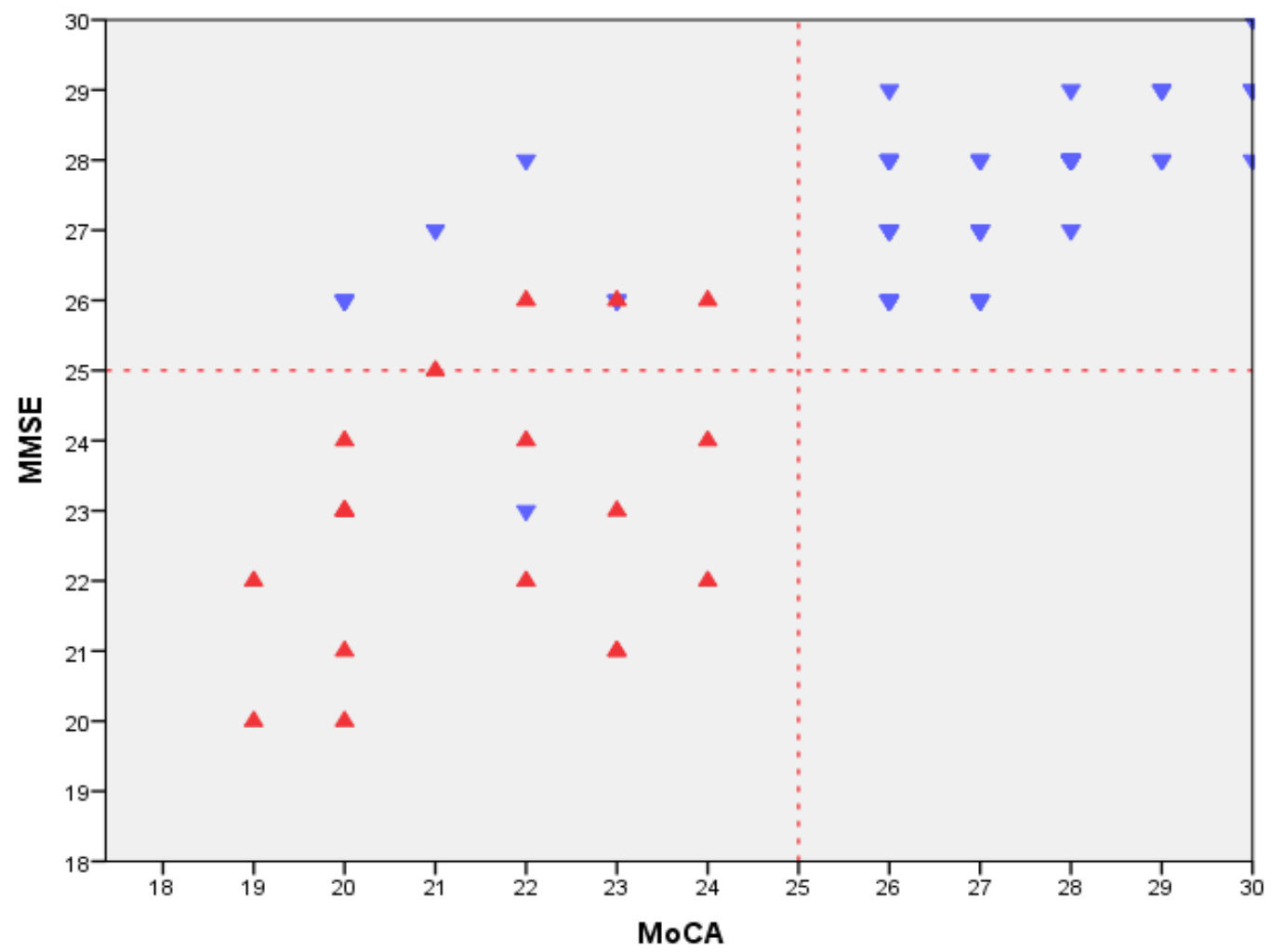

Table 1 Contingency table for the MMSE and the MoCA cut off with dementia diagnosis

\begin{tabular}{|c|l|c|c|c|c|}
\hline \multirow{2}{*}{2} & \multicolumn{2}{c|}{ MMSE } & \multicolumn{2}{c|}{ MoCA } \\
\cline { 3 - 6 } \multicolumn{2}{|c|}{} & $\begin{array}{c}\mathbf{2 5} \text { and } \\
\text { less }\end{array}$ & $\mathbf{2 6}$ and more & $\begin{array}{c}\mathbf{2 5} \text { and } \\
\text { less }\end{array}$ & \\
\hline \multirow{2}{*}{ Dementia diagnosis } & No & 64 & 1 & 55 & 10 \\
\cline { 2 - 6 } & Yes & 3 & 16 & 0 & 19 \\
\hline \multicolumn{2}{|c|}{ Total } & $\mathbf{6 7}$ & $\mathbf{1 7}$ & $\mathbf{5 5}$ & $\mathbf{2 9}$ \\
\hline
\end{tabular}

MMSE specificity was very good, and that was at the level $=0.99$ with $95 \%$ confidence interval from 0.92 to 0.99 . The MoCA specificity was good, and that was at the level $=0.85$ with $95 \%$ of the confidence interval from 0.73 to 0.91 .

In accordance with the foreign studies (Amieva et al., 2014; Imtiaz et al., 2014;
Trzepacz et al., 2015), we have demonstrated a good internal consistency for both methods, which means that these screening methods are stable at the time and they provide reliable measurements of cognitive deficit. Further on, the MoCA had a very good concurrent validity with the MMSE. This result has been expected because both 
of the tests are overlapped to a certain extent (there are the same tasks and some of them very similar). Based on our findings, we may state that the MMSE as well as the MoCA are adequately reliable screening tests. The alpha value found by us (the MMSE $\alpha=0.78 /$ the MoCA $\alpha=0.81$ ) is lower than the value specified by the MoCA method author $(\alpha=0.83)$ (Nasreddine et al., 2005); but despite that, these reliability values are sufficient and they are also in accordance with the research findings of the performed psychometric studies (Roalf et al., 2013; Saczynski et al., 2015).

Sensitivity and specificity of the MMSE are different in various stages depending on the cut off used. The original limit value was determined for 23 points and less - none of the examined persons without cognitive deficit from Folstein's study had less than 24 points. Later studies showed low sensitivity of this critical value (around (0.6), but high specificity (over 0.96) (Arevalo-Rodriguez et al., 2015; Kukull et al., 1994). Other studies showed that the cut off $24 / 23$ reaches 0.8 of the sensitivity for individuals with variously serious dementia, but the sensitivity of 0.54 for mild form of dementia (Schramm et al., 2002). Similarly, also in individuals with university education (having been educated for more than 16 years) the original cut off was shown to be a little sensitive (0.66). Nasreddine et al. (2005) found the sensitivity of only 0.18 with the critical score of 26 points for detection of mild cognitive impairment. With the same cut off, the sensitivity for dementia detection of Alzheimer's type was 0.78 and the specificity was 1 . The MMSE is also used as a classical screening tool for cognitive disorder diagnostics in Parkinson's disease. For this purpose, however, the MMSE seems to be a little specific tool. Hoops et al. (2009) recommend increasing of the limit value for the best ratio of sensitivity and specificity of the test in order to record cognitive disability in subjects with Parkinson's disease for the cut off of 28/29 points (sensitivity $=0.78$; specificity $=0.63$ ). The data about the MoCA sensitivity and specificity differ in various studies. The original work of the method author specifies the MoCA sensitivity with the cut off of $26 / 25$ points for mild cognitive impairment 0.9 and 1 for dementia. Specificity is specified at 0.87 (for dementia detection). In contrast with the MMSE, within the MoCA there are almost no patients with mild cognitive impairment or patients with dementia do not have the score over 25 points (Nasreddine et al., 2005). Some studies confirmed original psychometric features of the test (Litvan et al., 2012; Steenoven et al., 2014). Rossetti et al. (2011) found that the limit value of 26 points for specification of cognitive pathology may be strict a little and it is necessary to decrease it. Due to the fact that the MoCA is still only a supplementary test to the MMSE being used as a routine, Koski et al. (2011) tried to combine both of the tests and verify their diagnostic value. The use of the MoCA showed to be as the most convenient to the diagnostics of mild cognitive deficits with addition of 5 most difficult items from the MMSE (repetition of 3 words, recollection of 3 words, a sentence repetition, writing, and drawing of a pentagon). Thanks to some studies, from the results of the MoCA it is possible to easily assess a probable score of the MMSE (Saczynski et al., 2015). Our findings about sensitivity and specificity of both screening methods are comparable with the previous studies. Sensitivity of the MMSE was good at the level of 0.83 and sensitivity MoCA was very good at the level of 0.98 . Specificity of the MMSE was very good at the level $=0.99$ and specificity of the MoCA was good at the level $=0.85$ (Nasreddine et al., 2005). Even though the results of our study are significantly consistent with 
the previous findings, it is also necessary to mention limitations of our research. With regard to non-random selection, we are aware of our examined group limitation that it may not be generalisable. The gained examined group is relatively small and non-representative in terms of the Slovak population of geriatric patients, which was caused by occasional and non-random selection of subjects. The selection method was defined particularly with regard to its feasibility in practice and also it was influenced by our economic and temporal possibilities.

\section{Conclusion}

Cognitive functions evaluation by measuring tools has become a part of clinical practice not only in geriatrics, geriatric psychiatry, but also in the field of nursing research and practice. The measuring tools are predominantly recommended for the area of assessment and diagnostics in the literature. Screening tests provide information about a global cognitive status of a person without demanding neuropsychological examination. They are frequently used in research as a criterion classifying the persons who are examined into individual groups. They are appropriate for routine verification of the health status of certain populations with higher likelihood of certain disease incidence. Some methods are developed for global cognitive deficit diagnostics, some for specific disorders diagnostics and others are relevant only for differential diagnostics. Most of the methods serving for dementia detection are designed for all-purpose examination of cognitive deficit (Barker, Board, 2012). Due to reduction of load being laid on the patient as well as efficiency of measuring tools usage it is not necessary to use several measuring tools, between which there is a strong scale of correlation, and it is appropriate to choose a representative tool. Based on our as well as previous research findings, the MoCA method seems to be more effective for cognitive disorders screening of geriatric patients.

\section{References}

1. AMIEVA, H. - MOKRI, H. - LE GOFF, M. - MEILLON, C. - JACQMIN-GADDA, H. - FOUBERT-SAMIER, A. - ORGOGOZO, J.-M. - STERN, Y. - DARTIGUES, J.-F. Compensatory mechanisms in higher-educated subjects with Alzheimer's disease: a study of 20 years of cognitive decline. Brain, 2014. vol. 137, pp. 1167-1175. ISSN 0006-8950.

2. AREVALO-RODRIGUEZ, I., SMAILAGIC, N., ROQUE, I.F.M., CIAPPONI, A., SANCHEZ-PEREZ, E., GIANNAKOU, A., PEDRAZA, O.L., BONFILL COSP, X., CULLUM, S. Mini-Mental State Examination (MMSE) for the detection of Alzheimer's disease and other dementias in people with mild cognitive impairment (MCI). Cochrane Database Syst Rev. 2015, vol. 3, no. 1, p. 72. ISSN 1469-493X.

3. BARKER, S. - BOARD, M. Dementia Care in Nursing. 1. vyd. Cambridge: SAGE Publications, 2012. 184 s. ISBN 9780857258014.

4. FOLSTEIN, M.F. - FOLSTEIN, S.E. MCHUGH, P.R. "Mini-mental state": a practical method for grading the cognitive state of patients for the clinician. J Psychiatr Res, 1975. vol. 12.

5. HOOPS, S. - NAZEM, S. - SIDEROWF, A.D. - DUDA, J.E. - XIE, S.X. - STERN, M.B. - WEINTRAUB, D. Validity of the $M o C A$ and MMSE in the detection of MCI and dementia in Parkinson disease. Neurology, 2009. vol. 73 , no. 21 , pp. 1738-1745. ISSN 0028-3878.

6. IMTIAZ, B. - TOLPPANEN, A.-M. - KIVIPELTO, M. - SOININEN, H. Future directions in Alzheimer's disease from risk factors to prevention. Biochemical Pharmacology, 
2014. vol. 88, no. 4, pp. 661-670. ISSN 0006-2952.

7. KOSKI, L. - XIE, H. - KONSZTOWICZ, $\mathrm{S}$. Improving precision in the quantification of cognition using the Montreal Cognitive Assessment and the Mini-Mental State Examination. Int Psychogeriatr, 2011. vol. 23, no. 7, pp. 1107-1115. ISSN 1041-6102.

8. KUKULL, W.A. - LARSON, E.B. - TERI, L. - BOWEN, J. - MCCORMICK, W. PFANSCHMIDT, M.L. The Mini-Mental State Examination score and the clinical diagnosis of dementia. J Clin Epidemiol, 1994. vol. 47, no. 9, pp. 1061-1067. ISSN 0895-4356.

9. LITVAN, I. - GOLDMAN, J.G. - TROESTER, A.I. - SCHMAND, B.A. WEINTRAUB, D. - PETERSEN, R.C. - MOLLENHAUER, B. - ADLER, C.H. MARDER, K. - WILLIAMS-GRAY, C.H. - AARSLAND, D. - KULISEVSKY, J. RODRIGUEZ-OROZ, M.C. - BURN, D.J. - BARKER, R.A. - EMRE, M. Diagnostic criteria for mild cognitive impairment in Parkinson's disease: Movement Disorder Society Task Force guidelines. Movement Disorders, 2012. vol. 27, no. 3, pp. 349-356. ISSN 0885-3185.

10. MAUK, K.L. Gerontological Nursing. 2. vyd. Massachusetts: Jones \& Bartlett Learning, LLC, 2013. 1062 s. ISBN 9781449694647.

11. NASREDDINE, Z.S. - PHILLIPS, N.A. - BEDIRIAN, V. - CHARBONNEAU, S. - WHITEHEAD, V. - COLLIN, I. - CUMMINGS, J.L. - CHERTKOW, H. The montreal cognitive assessment, MoCA: A brief screening tool for mild cognitive impairment. Journal of the American Geriatrics Society, 2005. vol. 53, no. 4, pp. 695-699. ISSN 0002-8614.

12. ROALF, D.R. - MOBERG, P.J. - XIE, S.X. - WOLK, D.A. - MOELTER, S.T. - ARNOLD, S.E. Comparative accuracies of two common screening instruments for the classification of Alzheimer's disease, mild cognitive impairment and healthy aging. Alzheimer's \& Dementia: The Journal of the Alzheimer's Association, 2013. vol. 9, no. 5, pp. 529-537. ISSN 1552-5260.

13. ROSSETTI, H.C. - LACRITZ, L.H. - CULLUM, C.M. - WEINER, M.F. Normative data for the Montreal Cognitive Assessment (MoCA) in a population-based sample. Neurology, 2011. vol. 77, no. 13, pp. 12721275. ISSN 0028-3878.

14. SACZYNSKI, J.S. - INOUYE, S.K. GUESS, J. - JONES, R.N. - FONG, T.G. - NEMETH, E. - HODARA, A. - NGO, L. MARCANTONIO, E.R. The Montreal Cognitive Assessment: Creating a Crosswalk with the Mini-Mental State Examination. Journal of the American Geriatrics Society, 2015. vol. 63, no. 11, pp. 2370-2374. ISSN 0002-8614.

15. SCHRAMM, U. - BERGER, G. - MULLER, R. - KRATZSCH, T. - PETERS, J. - FROLICH, L. Psychometric properties of Clock Drawing Test and MMSE or Short Performance Test (SKT) in dementia screening in a memory clinic population. Int $\mathrm{J}$ Geriatr Psychiatry, 2002. vol. 17, no. 3, pp. 254260. ISSN 0885-6230.

16. SMITH, G.E. - BONDI, M.W. Mild Cognitive Impairment and Dementia: Definitions, Diagnosis, and Treatment. 1 ed. London: OUP USA, 2013. 403 pp. ISBN 9780199764181.

17. STEENOVEN, I. - AARSLAND, D. HURTIG, H. - CHEN-PLOTKIN, A. DUDA, J.E. - RICK, J. - CHAHINE, L.M. - DAHODWALA, N. - TROJANOWSKI, J.Q. - ROALF, D.R. - MOBERG, P.J. - WEINTRAUB, D. Conversion between Mini-Mental State Examination, Montreal Cognitive Assessment, and Dementia Rating Scale-2 scores in Parkinson's disease. Movement Disorders, 2014. vol. 29, no. 14, pp. 1809-1815. ISSN 1531-8257.

18. TAVAKOL, M. - DENNICK, R. Making sense of Cronbach's alpha. Int J Med Educ, 2011. vol. 2, pp. 53-55. 
19. TOPINKOVÁ, E. - JIRÁK, R. - KOŽENÝ, J. Short battery neurocognitive screening for dementia in clinical practice: a seven-minute screening test. Neurology for Practice, 2002. vol. 6, no. 2, p. 323-328.

20. TRZEPACZ, P.T. - HOCHSTETLER, H. WANG, S. - WALKER, B. - SAYKIN, A.J. Relationship between the Montreal Cognitive Assessment and Mini-mental State Examination for assessment of mild cognitive impairment in older adults. BMC Geriatrics, 2015. vol. 15, no. 1, pp. 1-9. ISSN 1471-2318.
21. TUOKKO, H.A. - HULTSCH, D.F. Mild Cognitive Impairment: International Perspectives. 1 ed. New York: Taylor \& Francis, 2013. 336 pp. ISBN 9781134953820. 